This is not the Version of Record - the full text can be found at:

http:/ / dx.doi.org/ 10.7748/ ns.2018.e10829 


\title{
Clinical management of non-healing wounds
}

NS934 Chamanga ET (2017) Clinical management of non-healing wounds. Nursing Standard.

Date of submission: 9 February 2017; date of acceptance: 9 October 2017. doi: 10.7748/ns.2017.e10829

\section{Edwin Tapiwa Chamanga}

Tissue viability service lead, Hounslow and Richmond Community Health, London, England

Senior lecturer in Primary Care \& Tissue Viability, Kingston and St Georges University London

\author{
Correspondence \\ e.chamanga@sgul.kingston.ac.uk \\ @edwin_chamanga
}

Conflict of interest

None declared

Peer review

Revalidation

Online

To write a CPD article

\section{Abstract}

This article discusses the assessment and treatment of non-healing chronic wounds. Chronic wounds represent a significant burden on healthcare resources and can have a negative effect on patients' quality of life. Chronic wounds are defined as those which have failed to heal after three months for various intrinsic and extrinsic factors, including comorbidities such as diabetes mellitus and venous insufficiency, as well as lifestyle factors such as obesity, alcohol consumption and smoking. This article also examines the normal wound-healing process and the management of chronic wounds, including advanced interventions such as electric stimulation therapy, debridement techniques and wound dressings. The author does not focus on specific wound types; instead, the article provides an overview of factors that can lead to the development of chronic wounds and how these can be managed in clinical practice.

\section{Keywords}

chronic wounds, extracellular matrix, infection, inflammation, matrix metalloproteinases, non-healing wounds, normal wound healing, wound bed preparation 


\section{Aims and intended leaning outcomes}

This article aims to explore the development of chronic wounds and their management in clinical practice. It also examines the normal wound-healing trajectory to demonstrate the points at which a healing wound can become a chronic non-healing wound. Chronic wounds are also known as hard-to-heal wounds, non-healing wounds, recalcitrant wounds, and challenging or complex wounds (Legerstee 2009, Vowden 2011). After reading this article and completing the time out activities you should be able to:

- Explain the normal wound-healing process.

- Identify the intrinsic and extrinsic factors that can lead to the development of chronic wounds.

- Understand the principles of wound management.

- Outline the wound management interventions that can be used to manage chronic wounds.

\section{Relevance to The Code}

????

\section{Introduction}

Chronic wounds are defined as those that fail to heal within a predicted timeframe (Frykberg and Banks 2015). The majority of wound care protocols recommend the use of standard wound care, for example debridement and application of a suitable wound dressing, for an initial period of four weeks, at which time the wound should be reassessed for any reductions in area and signs of healing, such as healthy granulation tissue (Frykberg and Banks 2015). A wound that has not progressed along the healing trajectory after three months is often considered to be chronic (Iqbal et al 2017).

Wounds that commonly become chronic include pressure ulcers, diabetic foot ulcers, leg ulcers and non-healing surgical wounds (Frykberg and Banks 2015). The prevalence of chronic wounds is rising, partly because of ageing populations and increased longevity (Probst et al 2014, Moore et al 2014). However, it is important to note that chronic wounds do not only affect older people, but can also affect younger people, depending on the individual's physical status. For example, patients whose mobility is reduced following surgery are at increased risk of developing chronic pressure ulcers (Health Quality Ontario, 2009).

During the normal wound-healing process, a balance of healthy proteins and enzymes, including neutrophils (a type of immune cell that combats infection by ingesting microorganisms), macrophages (a type of white blood cell that consumes cellular debris) and proteases (enzymes that control complex tissue functions such as cell proliferation) promote healing in the wound bed. Any disruption in this balance can result in the development of a chronic wound (Harding et al 2002, Gethin 2007, McCarty and Percival 2013). For example, elevated protease activity is a feature of chronic inflammation (Guo and DiPietro 2010). Intrinsic factors, such as older age or the presence of comorbidities such as diabetes, and extrinsic factors such as lifestyle factors and medication, can both affect the chemical balance in the wound bed.

Chronic wounds develop when wounds, especially in older patients and those exhibiting ischaemia, neuropathy and immobility, are not managed in a systematic way and are associated with the following features (Price and Harding 2004, Fong and Wood 2006, McCarty and Percival 2013, Rüttermann et al 2013, Vowden and Vowden 2016, Järbrink et al 2017): 
- Increased risk of infection and a build-up of bacterial bioburden, which occurs when bacterial cells secrete a variety of enzymes and toxins into the wound.

- High levels of exudate and pain, which result suboptimal quality of life.

- Use of long-term treatments; this is because chronic wounds are often 'stuck' in one phase of the normal woundhealing process.

- Financial burden to patients, for example in loss of earnings, and to healthcare providers.

- Emotional distress to patients, for example anxiety exacerbated by disturbed sleep.

- Reduced mobility, depending on the location of the wound; for example, leg ulcers and diabetic foot ulcers.

- Presence of multiple comorbidities that affect the usual wound-healing process.

Guest et al (2015) estimated that the cost of wound management to the NHS was $£ 5.3$ billion per year, while Posnett and Franks (2008) estimated that the management of chronic wounds costs the NHS approximately $£ 2.3-£ 3.1$ billion each year. Chronic wounds are prevalent in adults aged over 65 years (Rüttermann et al 2013, Gould et al 2015), and the cost of managing this patient group is likely to rise as the population ages and there is an increase in the incidence of comorbidities such as arterial insufficiency, venous insufficiency, diabetes mellitus or pressure that can negatively affect the wound-healing process (Fonder et al 2008, Rüttermann et al 2013).

It has been suggested that early identification of chronic wounds and the use of effective treatments are essential in improving patient outcomes and reducing the financial burden on the NHS (Guest et al 2015, Vowden and Vowden 2016). Diagnostic tools and clinical algorithms are available to support nurses in the identification of chronic wounds, for example, the TIME framework assists nurses in identifying the status of the wound bed (Dowsett et al 2015a) and the triangle of wound assessment encourages nurses to consider the wound bed, wound edge and periwound skin when undertaking any assessment of chronic wounds (Dowsett et al 2015b). Similarly, innovative techniques for the assessment of chronic wounds include a point-of-care test that detects elevated protease activity, which can cause chronic inflammation and impede wound healing (National Institute for Health and Care Excellence (NICE) 2016a). Advanced topical dressings have also been designed, which are aimed at reducing the amount of proteinase on the wound bed, thus reducing the risk of wound chronicity (Gardner 2013).

\section{TIME OUT 1}

In your own words, list the differences between a chronic wound and a wound that is healing normally. Using your notes, prepare a short teaching session for your colleagues on how to distinguish between a chronic and a non-healing wound.

\section{Normal wound-healing}

Wound healing is a complex and dynamic process by which the skin repairs itself (Meyers and Hudson 2013). It is characterised by a series of events that occur from the time of the injury to the point of wound healing and which are classed in four phases: haemostasis; inflammation; proliferation; and remodelling (Brown 2015). However, in clinical practice, these phases often overlap and some wounds become 'stuck' in one phase, predominantly the inflammatory phase, which can lead to the development of a chronic wound (Fonder et al 2008, McCarty and Percival 2013). Table 1 outlines the normal phases involved in the wound-healing process (Stacey 2016).

Table 1. Usual phases of the wound-healing process

\begin{tabular}{|l|l|l|l|l|}
\hline Phase & Timeframe & Cells involved & Function of activity & Cellular and biophysical events \\
\hline
\end{tabular}




\begin{tabular}{|c|c|c|c|c|}
\hline Haemostasis & Immediate & $\begin{array}{l}\text { Platelets (also called thrombocytes } \\
\text { and involved in blood clotting) }\end{array}$ & Clotting & $\begin{array}{l}\text { - } \quad \text { Vascular constriction } \\
\text { Platelet aggregation, } \\
\text { degranulation, and fibrin } \\
\text { formation (thrombus) }\end{array}$ \\
\hline Inflammation & Day 1-4 & $\begin{array}{l}\text { - Monocytes (a type of white } \\
\text { blood cell that can differentiate } \\
\text { into macrophages) } \\
\text { - Lymphocytes (a type of white } \\
\text { blood cell that forms part of the } \\
\text { immune system) } \\
\text { - Neutrophils (a type of white } \\
\text { blood cell that combats infection } \\
\text { by ingesting microorganisms) } \\
\text { - Macrophages (a type of white } \\
\text { blood cell that consumes cellular } \\
\text { debris) }\end{array}$ & $\begin{array}{l}\text { Phagocytosis (ingestion } \\
\text { of bacteria) }\end{array}$ & $\begin{array}{l}\text { - Neutrophil infiltration } \\
\text { - Monocyte infiltration, and } \\
\text { differentiation of } \\
\text { macrophages } \\
\text { - Lymphocyte infiltration }\end{array}$ \\
\hline Proliferation & Day 4-21 & $\begin{array}{l}\text { - Macrophages } \\
\text { - } \quad \text { Anmphocytes } \\
\text { the production of blood vessels) } \\
\text { - Neutrophils } \\
\text { - Fibroblasts (cells that promote } \\
\text { the development of connective } \\
\text { tissue, for example, the } \\
\text { extracellular matrix) } \\
\text { - Keratinocytes (epidermal cell } \\
\text { that produces keratin, one of the } \\
\text { main components of the } \\
\text { epidermis) }\end{array}$ & $\begin{array}{l}\text { - } \text { Re-establishment of } \\
\text { skin function } \\
\text { - Wound bed filling } \\
\text { - Wound closure }\end{array}$ & $\begin{array}{l}\text { - } \text { Re-epithelialisation } \\
\text { - } \text { Angiogenesis (growth of } \\
\text { new capillaries) } \\
\text { - Collagen synthesis }\end{array}$ \\
\hline Remodelling & Day 21-year 2 & $\begin{array}{l}\text { Fibrocytes (cells that circulate in the } \\
\text { bloodstream and produce proteins } \\
\text { that promote connective tissue } \\
\text { production) }\end{array}$ & $\begin{array}{l}\text { - Develop tensile } \\
\text { strength }\end{array}$ & $\begin{array}{l}\text { - Collagen remodelling } \\
\text { - Vascular maturation and } \\
\text { regression }\end{array}$ \\
\hline
\end{tabular}

\section{Haemostatic phase}

The first phase of the normal wound-healing process involves haemostasis. This begins as the blood vessels constrict (vasoconstriction), the platelets aggregate, and a clot is formed to prevent excess blood loss (Ng 2010).

\section{Inflammatory phase}


Inflammation is predominantly characterised by the presence of neutrophils and macrophages in the wound bed and surrounding tissue, which combat any invading harmful microorganisms or foreign materials (Harding et al 2002). As the wound moves through the phases of the wound-healing process, neutrophils reduce in numbers and are replaced by macrophages (Meyers and Hudson 2013), which have three major functions (Fujiwara and Kobayashi 2005):

- Antigen presentation - once a macrophage has digested a pathogen, it will display, or 'present' any associated antigens to so-called 'helper' T-cells, which assist other white blood cells with immunologic processes.

- $\quad$ Phagocytosis - ingestion of bacteria.

- Immunomodulation - changes the body's immune function, for example, to fight infection.

\section{Proliferative phase}

In the proliferation phase, new granulation tissue is formed, which comprises microscopic blood vessels and elements that form the extracellular matrix (ECM), for example polysaccharides and elastin and collagen proteins. The ECM surrounds and supports cells in the body's tissues and is the main component of the dermal skin. Fresh granulation tissue has a pink appearance and begins to fill the wound bed from the base upwards to the skin level, where epithelialisation will occur in the next phase of wound healing (Meyers and Hudson 2013). The growth of fresh granulation tissue is supported by angiogenesis (the formation of capillaries) (Martin 2013).

\section{Remodelling phase}

Remodelling is the final stage of wound healing, in which the collagen content of the wound changes to become smoother and new epithelial cells adjacent to the wound migrate across the wound surface (Leoni et al 2015). Cells that were required to repair the wound are removed by apoptosis (programmed cell death). The remodelling phase involves closure of the wound edges (Meyers and Hudson 2013). It should be noted that, following total wound closure, the tissue on the healed wound site will only retain $70-80 \%$ of the tensile strength of the original tissue (Meyers and Hudson 2013).

\section{TIME OUT 2}

Explain the four phases of the usual wound-healing process and the events that occur in each phase to a colleague. Think about the factors that led to any acute wounds you have encountered becoming chronic wounds.

\section{The role of matrix metalloproteinases}

Matrix metalloproteinases (MMPs) are enzymes that are essential for the wound-healing process. MMPs are produced by activated inflammatory cells (neutrophils and macrophages) and other cells involved in wound healing, for example, epithelial cells and fibroblasts (cells that promote the development of connective tissue) (Gibson et al 2009) (Table 1). The role of MMPs is to (Armstrong and Jude 2002, Gibson et al 2009):

- Remove damaged ECM and bacteria.

- Prepare the capillary basement membrane for angiogenesis.

- Support the migration of epidermal cells.

- Enable ECM contraction and scar remodelling.

\section{Development of chronic wounds}

Chronic wounds commonly include vascular ulcers (including venous and arterial ulcers), pressure ulcers and diabetic ulcers. Features of chronic wounds include (Frykberg et al 2015): 
- Prolonged inflammation.

- Infection.

- Formation of microbial biofilms.

- Inability of skin cells to repair the wound.

\section{Chemical imbalance}

Disruption of the normal wound-healing process involves chemical imbalances in the wound bed that can lead to the development of a chronic wound (Gethin 2007, Guo and DiPietro 2010, Sussman 2014). For example, inflamed tissue at the wound site attracts neutrophils and macrophages, which, in turn release reactive oxygen species (ROS), proteases and MMPs. While these factors are necessary to combat bacteria, they can also damage cells when not properly regulated (Eleri et al 2015). An over-production of MMPs, for example, and a reduced secretion of tissue inhibitor of metalloproteinase (TIMPS) (proteins that inhibit MMPs and regulate the production and deactivation of ECM), over a prolonged period will begin to damage the proteins required for wound healing, leading to degradation of the ECM and a chronic wound (Gibson et al 2009, McCarthy and Percival 2013).

There are several intrinsic and extrinsic factors that can cause chemical imbalances in the wound bed. Intrinsic factors relate to the overall health or disease state of the individual patient that negatively affect the wound-healing process. It is not always possible to modify intrinsic factors, such as the patient's age or comorbidities such as diabetes, which can affect the chemical balance in the wound bed. In contrast, extrinsic factors, which include external variables such as medication, alcohol consumption, smoking and infection, can be eliminated or modified to enable the wound to move from a chronic state onto a normal wound-healing trajectory.

\section{Intrinsic factors}

Age

Ageing results in changes to the structure and function of the skin, which may impair the rate and quality of the wound-healing process. For example, the skin of older adults is more fragile, thinner, less elastic and drier than in younger adults, with new cells being generated more slowly (Vowden 2011, Meyers and Hudson 2013). In addition, the fatty content of the subcutaneous tissue, which protects against infections and trauma, decreases in older adults (Visser et al 2003, Raguso et al 2006, Tchkonia et al 2010). However, the major challenges associated with longevity are that patients present with multiple comorbidities and polypharmacy, which can negatively affect the woundhealing process (Anderson and Hamm 2012, Gould et al 2015).

Stress

Sternberg (2006) reported that stress disrupts the neuroendocrine immune equilibrium, which causes a substantial delay in wound healing by prolonging the inflammation phase. A prolonged inflammatory phase results in higher bacterial counts and increases the incidence of infection, which delays wound closure and the healing process (Engeland and Marucha 2009). Stress can also lead to anxiety, depression, suboptimal sleeping patterns, inadequate nutrition, less exercise and an increased susceptibility to alcohol, cigarettes and other drugs, all of which have a negative effect on wound healing (Godbout and Glaser 2006).

\section{Diabetes}

Patients with a diagnosis of diabetes are at risk of presenting with multiple comorbidities, including suboptimal wound healing and chronic ulceration as a result of microvascular and macrovascular complications (Vowden 2011, Okonkwo and DiPietro 2017). While the diagnosis of diabetes does not automatically mean that a patient will develop a chronic wound, patients with suboptimally controlled blood glucose levels are at high risk of developing chronic 
wounds because of hypoxia (lack of oxygen), dysfunction in the role of fibroblasts and epidermal cells, and impaired angiogenesis and neovascularisation (the natural formation of new blood vessels) (Guo and DiPietro 2010).

\section{Nutrition}

Adequate nutritional intake is essential for the wound-healing process as some patients lose large volumes of protein through wound exudate, and patients with wounds have a higher metabolic rate compared to those without (Guo and DiPietro 2010, Gould et al 2015). There are many aspects of nutrition that influence the wound-healing process. For example, protein deficiency can impair capillary formation, cell proliferation and wound remodelling, as well as reducing the efficiency of the immune system, thereby increasing the risk of infection (Gould et al 2015). Other essential nutrients for wound healing include vitamins A, B, and C, zinc, iron and copper (Molnar et al 2014). A referral to the dietetics service for assessment may be required if a person with a wound is suspected of having a suboptimal nutritional intake.

Obesity and being underweight also have a negative effect on the wound-healing process. Patients who are obese are at risk of compromised wound healing as a result of inadequate blood supply to the adipose tissue or protein malnutrition, while patients who are underweight may lack the oxygen and nutritional stores required for wound healing (Stacey 2016).

\section{Extrinsic factors}

\section{Medication}

Some medicines such as cytotoxic drugs interfere with cell migration on the wound bed, and may cause neutropenia (a lack of infection-fighting neutrophils in the bloodstream), making the wound bed susceptible to wound infection (Fonder et al 2008, Guo and DiPietro 2010). The use of antiplatelet agents, long-term steroids and anti-inflammatory drugs suppresses the body's usual inflammation process or disrupts the clotting mechanism, thereby disrupting the wound-healing process by causing vasoconstriction (Bale et al 2000, Fonder et al 2008). As a result of prolonged vasoconstriction in the wound bed, the wound-healing process becomes disrupted, with inadequate numbers of macrophages reaching the wound bed site to facilitate the inflammation process (Gou and DiPietro 2010). This could potentially lead to the development of a chronic wound caused by a lack of growth factors or disruption from infection, because macrophages have major role in combatting microorganisms (Fujiwara and Kobayashi 2005).

\section{Alcohol consumption}

Alcohol consumption impairs wound healing and increases the incidence of infection by suppressing the release of pro-inflammatory enzymes (Tønnesen et al 2012). This is supported by evidence of decreased neutrophil activity and phagocytic action in patients who consume alcohol (Tønnesen et al 2012). It should be noted that profound effects of alcohol on host defence depend on an acute or chronic pattern of alcohol consumption (Guo and DiPietro 2010). Excessive alcohol consumption (alcohol misuse) will significantly affect the wound-healing process in comparison to moderate alcohol intake, Radek et al., (2007).

\section{Smoking}

Smoking reduces the oxygen-carrying capacity of red blood cells, thereby inducing wound chronicity because the lack of oxygenated blood inhibits angiogenesis in the wound bed (Meyers and Hudson 2013). This is supported by Stacey (2016), who stated that nicotine causes vasoconstriction, which reduces blood flow to the skin. This results in tissue ischaemia, reduced proliferation of red blood cells, fibroblasts and macrophages, and impaired wound healing. 
One of functions of the skin is to provide protection to internal organs from external microorganisms; however, once the skin is injured the underlying tissue can become contaminated (Edwards and Harding 2004). It is essential that the contaminating microorganisms are removed or reduced, so that the inflammation phase of the wound-healing process is not prolonged (Gould et al 2015). The major function of neutrophils is to remove foreign material, bacteria and non-functional tissue, which may be present in the wound bed (Hart 2002). Phagocytosis occurs when neutrophils identify the chemical signals displayed by microorganisms and ingest them (Hart 2002, Sylvia 2003).

\section{TIME OUT 3}

Write down the differences between intrinsic and extrinsic factors that influence wound chronicity. How do they affect the normal wound-healing process?

\section{Chronic wound management}

Both acute and chronic wound management involves holistic assessment and ongoing evaluations of the wound bed to support wound healing and improve quality of life (Ousey and Atkin 2013). It is important that chronic wounds are shifted back onto a normal healing trajectory. The first step in managing a chronic wound is to perform the holistic assessment, which includes a medical history, any intrinsic and extrinsic factors that may affect healing, and an assessment of the wound bed. Timely wound assessments and reviews support effective clinical decisionmaking, however, Gethin (2007) noted that the clinical assessment of chronic wounds is often based on subjective interpretation, with little objective analysis.

Table 2 demonstrates some of the objective tests that nurses can use to assist with the assessment of a patient's wound status, aetiology and comorbidities.

\begin{tabular}{|c|c|c|}
\hline Type of test & Assessments directly related to the wound & Other assessments \\
\hline $\begin{array}{l}\text { Physical tests and } \\
\text { observations }\end{array}$ & $\begin{array}{l}\text { - Wound dimensions - two or three- } \\
\text { dimensional } \\
\text { - Wound or periwound oedema, or } \\
\text { erythema/heat } \\
\text { - Wound bed - for example the type of tissue, } \\
\text { presence of exposed bone or tendon, colour, } \\
\text { odour } \\
\text { - Wound margin - for example undermining, } \\
\text { rolled edge } \\
\text { Surrounding skin and wound edge } \\
\text { characteristics - for example punched out } \\
\text { ulcers may be arterial, while oedema, } \\
\text { pigmentation and induration may indicate a } \\
\text { venous ulcer } \\
\text { Wound site - for example sacral wounds may } \\
\text { be pressure ulcers, lower leg wounds may be } \\
\text { arterial or venous ulcers }\end{array}$ & $\begin{array}{l}\text { - Temperature monitoring (pyrexia, } \\
\text { infection) } \\
\text { - } \text { Blood pressure monitoring } \\
\text { (hypertension) } \\
\text { - } \quad \text { Neurological examination- reflexes and } \\
\text { sensation (diabetic neuropathy) } \\
\text { - } \text { Arterial pulses, response to limb } \\
\text { elevation and lower limb rest pain } \\
\text { (peripheral arterial disease) }\end{array}$ \\
\hline
\end{tabular}




\begin{tabular}{|c|c|c|}
\hline & $\begin{array}{l}\text { - Colour, odour, viscosity and quantity of } \\
\text { exudate } \\
\text { - Presence, level and character of pain }\end{array}$ & \\
\hline Biological tests & $\begin{array}{l}\text { - Microbiological culture-qualitative and } \\
\text { quantitative (infection) } \\
\text { - Wound histology and cytology (vasculitis, } \\
\text { malignancy) }\end{array}$ & $\begin{array}{l}\text { - White cell count (infection) } \\
\text { - Erythrocyte sedimentation rate } \\
\text { (inflammation, infection) }\end{array}$ \\
\hline Biochemical tests & & $\begin{array}{l}\text { - } \text { Glucose (diabetes) } \\
\text { - } \text { Plasmoglobin (oxygenation) } \\
\text { - } \quad \text { Lipids (hypercholesterolaemia) } \\
\text { - Urea and electrolytes (renal function) } \\
\text { - Glycated haemoglobin (long-term } \\
\text { - } \text { control of diabetes) } \\
\text { (rheumatoid factor, autoantibodies } \\
\text { - disease) } \\
\text { C-reactive protein (inflammation, } \\
\text { infection) }\end{array}$ \\
\hline Others & & 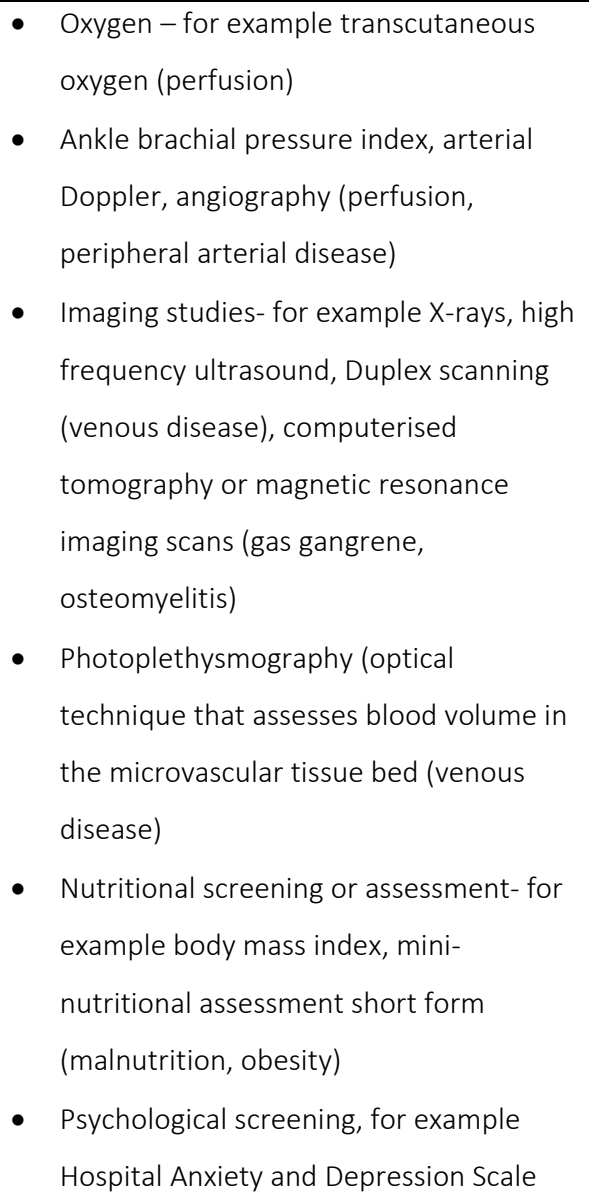 \\
\hline
\end{tabular}




\begin{tabular}{|l|l|l|}
\hline & & (depression, anxiety) \\
\hline (World Union of Wound Healing Societies 2008) \\
\hline
\end{tabular}

\section{TIME OUT 4}

Think about the main assessment techniques that can be used to identify a chronic wound. Have you had to assess a patient with a wound recently? Which of the techniques listed in Table 2 did you use? Would you use any alternative techniques in the future?

\section{Wound bed preparation}

Wound bed preparation is considered crucial to accelerate wound healing or to enhance the effectiveness of interventions designed to heal chronic wounds (Falanga 2000, Schultz et al 2003, European Wound Management Association 2004, Matiasek et al 2014). Wound bed preparation involves identifying and eliminating factors that may hinder the wound-healing process, such as nonviable tissue in the wound bed or increased exudate levels. This facilitates wound healing and provides an effective means of chronic wound management by (Schultz et al 2003):

- Promoting an understanding of the barriers to healing.

- Providing a systematic approach.

- Enhancing the effects of advanced therapies.

Wound bed preparation can be summarised using the TIME framework (Figure 1) (Dowsett et al 2015a), which consists of four components:

- $\mathrm{T}$ - is the tissue viable or non-viable? Is removal (debridement) of non-viable tissue, for example, necrotic tissue and eschar (dry 'scab'), necessary to encourage wound healing?

- I - infection or inflammation. Are there any visible clinical signs of infection, such as heat, redness, pain, swelling and odour, which need to be addressed to encourage the wound-healing process?

- $\quad \mathrm{M}$ - moisture imbalance. Is the wound environment moist enough to support the principle of moist wound healing?

- E - edges. Are the wound edges non-advancing or undermining (deep tissue damage around the wound margin)? What are the characteristics of the wound edges? Are they thick and non-advancing (callus)? If so, they may require debridement.

The TIME framework (Dowsett et al 2015a) provides nurses with a systematic approach to selecting appropriate wound interventions, and should be implemented as part of holistic assessment of any chronic wound. It can also identify appropriate wound bed objectives, which can often change during the wound-healing process, for example:

- Debride - to remove the nonviable tissue to encourage granulation.

- Hydrate - to moisten the wound bed to encourage moist wound healing or debridement.

- Protect - to keep the tissue in the wound bed free from trauma and contamination.

- Manage pain - to make sure that the patient is comfortable.

- Manage exudate - to encourage a moist environment and protect the periwound skin.

- Encourage granulation - to support the formation of new capillaries.

- Aid epithelialisation - to encourage total wound closure by ensuring that epithelial cells cover the wound bed.

- Reduce bacterial bioburden - to minimise the risk of infection. 


\section{Figure 1. Wound bed preparation using the TIME framework}

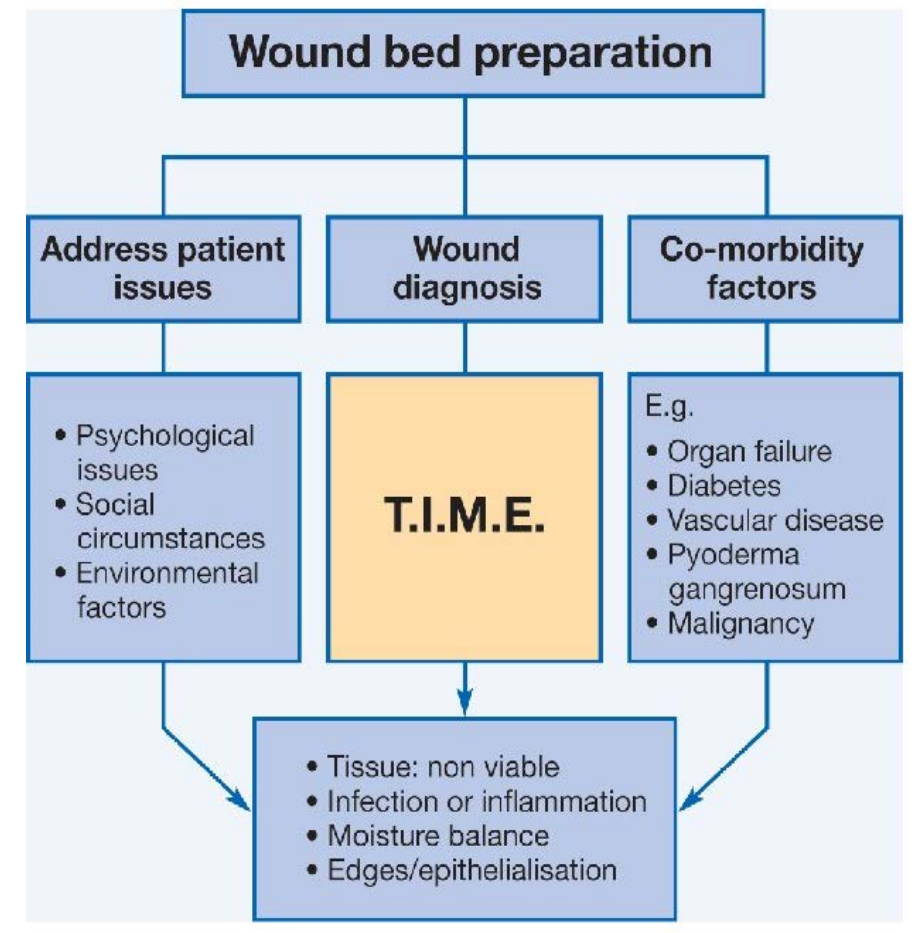

(Watret 2005)

One of the main principles of wound management is moist wound healing, a concept first posited by Winter (1962) and which states that the wound bed must be kept moist using conventional dressings to encourage wound healing. While this principle was initially based on managing acute wounds, it has been proven to be effective in managing chronic wounds (Hollinworth 2005). While the theory of wound bed preparation has largely superseded Winter's (1962) work, ensuring that the wound is adequately hydrated is one of the cornerstones of modern wound care and forms a crucial element of the TIME framework (Dowsett et al 2015a).

\section{Selecting an appropriate wound dressing}

The nurse and the patient should consult to choose an appropriate dressing or therapy to be used on the wound. Types of dressing include: passive dressings, interactive dressings and occlusive dressings (Table 3). Dressing section process is influenced by what needs to be achieved on the wound bed, is it debridement, hydration, desloughing or the promotion of granulating tissue as each dressing presents with its own unique properties (Chamanga, 2016).

As a result of the ongoing assessment process, at some point the nurse may also decide to refer the patient onto a specialist, particularly if the chronic wound continues to be resistant to treatment. For example, if a patient presents with compromised blood flow to the lower limbs, they may benefit from a consultation with a healthcare professional in the vascular department.

\section{Table 3. Types of dressing and their properties}

\begin{tabular}{|l|l|l|}
\hline Type & Examples & Properties \\
\hline Passive dressings & $\bullet$ Foams & $\bullet$ For low exudation and epithelialising wounds \\
& $\bullet$ Films & $\bullet$ Provide protection by covering the wound \\
\hline
\end{tabular}




\begin{tabular}{|c|c|c|}
\hline & - Silicone & - Provide protection against dehydration \\
\hline $\begin{array}{l}\text { Interactive } \\
\text { dressings }\end{array}$ & $\begin{array}{ll}\text { - } & \text { Alginates } \\
\text { - } & \text { Hydrocolloids } \\
\text { - } & \text { Hydrofibres } \\
\text { - Semi-permeable films } & \\
\text { - Some foams }\end{array}$ & $\begin{array}{l}\text { - For clean granulating wounds } \\
\text { - } \text { Actively interact with the wound surface by either filling space to } \\
\text { encourage granulation or resting on top of non-viable tissue to } \\
\text { encourage wound debridement } \\
\text { - } \quad \text { Promote optimal environment for wound healing } \\
\text { - } \text { Provide protection against dehydration } \\
\text { - Many interactive dressings are semi-impermeable to moisture } \\
\text { (occlusive), which promotes moisture balance, but not all }\end{array}$ \\
\hline Occlusive dressings & Hydrocolloids & $\begin{array}{l}\text { - Completely seal off the wound from the external environment } \\
\text { - Occlusive }\end{array}$ \\
\hline
\end{tabular}

\section{TIME OUT 5}

A 56-year-old patient with a history of hypertension and type 2 diabetes with suboptimal glycaemic control and peripheral vascular disease, presents with a diabetic foot ulcer on their right heel that is three months old. The wound measures $3.5 \mathrm{~cm}$ in length, $2.4 \mathrm{~cm}$ in width and less than $0.5 \mathrm{~cm}$ in depth. The wound bed consists of $50 \%$ slough and $50 \%$ pale granulation tissue. The periwound skin is macerated and wet. The wound also exhibits malodour and thick exudate, indicating that the wound is critically colonised. Consider the following:

- What are your treatment aims?

- How would you prepare the wound bed?

- Which dressings would you consider using?

- How could you explain to a colleague what is happening in the wound bed?

\section{Advanced interventions for chronic wounds}

\section{Biofilm removal}

Some chronic wounds exhibit colonies of bacteria that live in communities known as biofilms (James et al 2008). Biofilms are known to impair healing in chronic wounds as well as demonstrating tolerance to antimicrobial therapies and phagocytic cells (Phillips et al 2010). Biofilms are a precursor to wound infection and they lead to the development of chronic wounds because they typically present in wounds stuck in the inflammatory phase exhibiting high levels of MMPs, which can be a result of chemical imbalance in the wound bed (Phillips et al 2010). As a result of advances in technology and wound care research, irrigation solutions and gels that contain antimicrobial agents, for example, antiseptics such as polyhexanide that are active against Gram-negative and Gram-positive bacteria, have been developed that clean, moisten and decontaminate chronic wounds, thereby reducing the bacterial load in the wound bed (Horrocks 2006, Chamanga et al 2015).

Larval Therapy 
Wound debridement is an essential part of wound bed preparation process (Dowsett et al 2015a). In some chronic wounds this is achieved by the use of larval therapy (Chan et al 2007). Despite the availability of other debridement methods, such as autolytic debridement, where the body naturally rejects the dead tissue or mechanical (sharp) debridement, where the dead tissue has to be manually removed, larval debridement is unique and cannot be compared to the former two, as it is fast and very precise without damaging healthy tissue (Wolff \& Hansson, 2003).

Topical Negative Pressure Therapy

Following on to a successful wound debridement, the use of topical negative pressure therapy (TNPT) can be beneficial in managing chronic wounds (Armstrong \& Lavery, 2005). TNPT can benefit the wound by removing of excess fluid, which normally compromises the microcirculation, oxygen delivery, transportation of nutrients and waste products such as high levels of MMPs (Evans et al 2015). This will encourage the granulation process, supported by a health vascularisation as a result of increased local blood flow, reduced oedema and bacterial colonisation (Jones et al 2005).

\section{Electrical stimulation}

A review by Houghton (2017) found that electrical stimulation therapy (EST), where electrodes are placed on or around the wound and an electric current supplied to the area, stimulates tissue repair and wound closure in chronic wounds. While EST is understood to activate the nerves and muscles of the wound bed, the scientific process of EST is not fully understood. EST can be expensive; therefore, diagnostic processes identified in table 2 should be considered first before the prescription of EST (Houghton, 2017).

\section{Debridement pads and cloths}

NICE (2014) recognised monofilament pads as an effective wound debridement method. Debridement of chronic wounds using a monofilament pad removes dead or damaged tissue from the wound bed and can be undertaken in the community at relatively low cost (NICE 2014). Monofilament pads have also been found to be effective in breaking down biofilms in chronic wounds (Morris et al 2017, Wolcott 2016).

Pre-moistened single-use cloths are also available for chronic wound debridement and cleaning of the periwound skin, particularly in ulcers on the lower limb (Young, 2016). These cloths can remove necrotic material, moisten the wound bed and remove the necessity for nurses to use buckets of water when cleansing patient's leg ulcers in their own homes, for example.

\section{Dressings}

As well as the dressings listed in Table 3, there are several innovative types of wound care dressings aimed specifically at the treatment of chronic wounds (British National Formulary 2017). These contain a variety of antimicrobial agents including silver, polyhydrated ionogens (PHIs), which aim to restore MMP ratios in chronic wounds (Pirayesh et al, 2007), and protease-modulating dressings that may include, for example, nanooligosaccharide factor (oligosaccharides are a type of carbohydrate), a synthesised component that is designed to inhibit protease activity (NICE, 2016b).

\section{TIME OUT 6}

Think about whether you have recently encountered a patient with a chronic wound. Consider the treatments that were used in this case, and whether a more innovative treatment might have been tried. What would be your rationale for 
choosing an innovative treatment, and what effect you would expect it to have on the wound bed, for example, how would a protease-modulating dressing effect the cellular composition of the wound bed?

\section{Conclusion}

Chronic wounds remain a challenge in clinical practice, and involve significant costs, both in terms of healthcare providers' resources and patients' quality of life. Chronic wounds usually develop as a result of intrinsic and/or extrinsic factors, which lead the wound to become stuck in one of the wound-healing phases, predominantly the inflammatory phase.

When managing a patient with a chronic wound, it is important that nurses identify any presenting factors that may lead to wound chronicity as part of an holistic assessment, including a comprehensive medical history and undertaking tests that can indicate the presence of infection in the wound bed, for example.

The nurse should also understand the biological changes that take place in chronic wounds so that they can prescribe appropriate therapy, which may include conventional dressings or innovative treatments such as proteasemodulating dressings, NPWT or EST, depending on the objectives identified by the assessment.

While chronic wounds can be successfully treated, nurses should bear in mind how any innovative, and potentially expensive, interventions will interact with the chronic wound bed to ensure that cost-effective treatment is provided.

\section{TIME OUT 7}

Nurses are encouraged to apply the four themes of The Code (NMC 2015) to their professional practice. Consider how the management of chronic wounds relates to The Code.

\section{TIME OUT 8}

Now that you have completed the article, you might like to write a reflective account as part of your revalidation.

\section{References}

Anderson K, Hamm RL (2012) Factors that impair wound healing. The Journal of the American College of Clinical Wound Specialists. $4,4,84-91$.

Armstrong DG, Jude EB (2002) The role of matrix metalloproteinases in wound healing. Journal of the American Podiatric Medical Association. 92, 1, 12-18.

Armstrong, D. \& Lavery, L. (2005) Negative pressure wound therapy after partial diabetic foot amputation: A multicentre, randomised controlled trial. The Lancet, 366(9498): 1725-1735.

Bale S, Harding K, Leaper D (2000) An Introduction to Wounds. Emap Healthcare, London.

Brown A (2015) Phases of the wound-healing process. Nursing Times. 111, 46, 12-13.

Chamanga, E. (2016) Wound assessment and treatment in primary care. Independent Nurse. [Online]

http://www.independentnurse.co.uk/clinical-article/wound-assessment-and-treatment-in-primary-care/116877/

Chamanga ET, Hughes M, Hilston K et al (2015) Chronic wound bed preparation using a cleansing solution. British Journal of Nursing. 24, 12, S30-S36.

Chan, D., Fong, D., Leung, J., Patil, N., \& Leung, G. (2007) Maggot debridement therapy in chronic wound care. Hong Kong Medical Journal, 13(5): 382-386.

Dowsett C, Gronemann MN, Harding K (2015a) Taking wound assessment beyond the edge. Wounds International. 6, 1, 19-23.

Dowsett C, Protz K, Drouard M et al (2015b) Triangle of Wound Assessment: Made Easy.

www.woundsinternational.com/media/other-resources/_/1189/files/twa-made-easy_web.pdf (Last accessed: 17 November 2017.) 
Eaglstein WH (2001) Moist wound healing with occlusive dressings: a clinical focus. Dermatologic Surgery. 27, 2, $175-181$.

Edwards R, Harding KG (2004) Bacteria and wound healing. Current Opinion in Infectious Diseases. 17, 2, 91-96.

Engeland CG, Marucha PT (2009) Wound healing and stress. In Granstein RD, Luger TA (eds) Neuroimmunology of the Skin: Basic Science to Clinical Relevance. Springer-Verlag, Berlin, 233-247.

Eleri MJ, Cochrane CA, Percival SL (2015) The effect of Ph on the extracellular matrix and biofilms. Advances in Wound Care. 4, 7, 431-439.

European Wound Management Association (2004) Position Document: Wound Bed Preparation in Practice. Medical Education Partnership, London.

Evans, D., Land. L., \& Dumville, J. G. (2015) Topical negative pressure for treating chronic wounds.

http://onlinelibrary.wiley.com/doi/10.1002/14651858.CD001898.pub3/full

Falanga V (2000) Classifications for wound bed preparation and stimulation of chronic wounds. Wound Repair and Regeneration. 8, 5, 347-352.

Fonder MA, Lazarus GS, Cowan DA et al (2008) Treating the chronic wound: a practical approach to the care of nonhealing wounds and wound care dressings. Journal of American Academy of Dermatology. 58, 2, 185-206.

Fong J, Wood F (2006) Nacocrystalline silver dressings in wound management: a review. International Journal of Nanomedicine. 1, 4, 441-449.

Frykberg RG, Banks J (2015) Challenges in the treatment of chronic wounds. Advances in Wound Care. 4, 9, $560-582$.

Fujiwara N, Kobayashi K (2005) Macrophages in inflammation. Current Drug Targets. 4, 3, 281-286.

Gardner S (2013) Using treatment pathways to improve healing of venous leg ulceration. Wounds UK. 9, 1, 67-75.

Gethin G (2007) The significance of surface pH in chronic wounds. Wounds UK. 3, 3, 52-56.

Gibson D, Cullen B, Legerstee R et al (2009) MMPs Made Easy. Wounds International. 1, 1, 1-6.

Godbout JP, Glaser R (2006) Stress-induced immune dysregulation: implications for wound healing, infectious disease and cancer. Journal of Neuroimmune Pharmacology. 1, 4, 421-427.

Gould L, Adabir P, Brem H et al (2015a) Chronic wound repair and healing in older adults: current status and future research. Journal of the American Geriatrics Society. 63, 3, 427-438.

Guest JF, Ayoub N, McIlwraith T et al (2015) Health economic burden that wounds impose on the National Health Service in the UK. BMJ Open. 5, 12, e009283. doi:10.1136/bmjopen-2015-009283.

Guo S, DiPietro LA (2010) Factors affecting wound healing. Journal of Dental Research. 89, 3, 219-229.

Harding KG, Morris HL, Patel GK (2002) Healing chronic wounds. BMJ. 324, 160-163. doi: 10.1136/bmj.324.7330.160.

Hart J (2002) Inflammation. 1: its role in the healing of acute wounds. Journal of Wound Care. 11, 6, $205-209$.

Health Quality Ontario (2009) Management of Chronic Pressure Ulcers. Ontario Health Technology Assessment Series; 9(3):1-203.

Hollinworth H (2005) The management of patients' pain in wound care. Nursing Standard. 20, 7, 65-73.

Horrocks A (2006) Prontosan wound irrigation and gel: management of chronic wounds. British Journal of Nursing. 15, 22, 12221228.

Houghton PE (2017) Electrical stimulation therapy to promote healing of chronic wounds: a review of reviews. Chronic Wound Care Management and Research. 2017, 4, 25-44.

Iqbal A, Jan A, Wajid MA et al (2017) Management of chronic non-healing wounds by hirudotherapy. World Journal of Plastic Surgery. 6, 1, 9-17.

James GA, Swogger E, Wolcott R et al (2008) Biofilms in chronic wounds. Wound Repair and Regeneration. 16, 1, 37-44.

Järbrink K, Ni G, Sönnergren H et al (2017) The humanistic and economic burden of chronic wounds: a protocol for a systematic review. 6, 15. doi: 10.1186/s13643-016-0400-8.

Jones, S., M., Banwell, P. E., \& Shakespeare, P.G. (2005) Advances in wound healing: topical negative pressure therapy. Postgrad Medical Journal; 81:353-357.

Legerstee R (2009) The 'chronic' wound debate. Wounds International. 1, 1, 1-2.

Leoni G, P-A Neumann A, Sumagin R et al (2015) Wound repair: role of immune-epithelial interactions. Mucosal Immunology 8, 5, 959-968.

Moore Z, Butcher G, Corbett LQ et al (2014) Exploring the concept of a team approach to wound care: managing wounds as a team. Journal of Wound Care. 23, Suppl 5b, S1-S38.

Martin M (2013) Physiology of wound healing. In Flanagan M (Ed) Wound Healing and Skin Integrity: Principles and Practice. John Wiley \& Sons, Chichester, 33-51. 
Matiasek J, Djedovic G, Mattesich M et al (2014) The combined use of NPWT and instillation using an octenidine based wound rinsing solution: a case study. Journal of Wound Care. 23, 11, 590-596.

McCarty SM, Percival SL (2013) Proteases and delayed wound healing. Advances in Wound Care. 2, 8, 438-447.

Meyers L, Hudson SL (2013) Wound Care: Getting to the Depth of the Tissue. www.nursece.com/pdfs/720_WoundCare.pdf (Last accessed: 30 January 2018.)

Molnar JA, Underdown MJ, Clark WA (2014) Nutrition and chronic wounds. Advances in Wound Care. 3, 11, 663-681.

Morris C, Timmons J, Sykes R et al (2017) The management of chronic wound biofilm with a monofilament fibre debridement biofilm pathway: results of an audit. Poster presented at XIV Congresso Nazionale Aiuc 'Vulnologia 2.0', Turin, Italy, October, 2017

National Institute for Health and Care Excellence (2014) The Debrisoft Monofilament Debridement Pad for Use in Acute or Chronic Wounds. Medical technologies guidance No. 17. NICE, London.

National Institute for Health and Care Excellence (2016a) Woundchek Protease Status for Assessing Elevated Protease Status in Chronic Wounds. Medtech innovation briefing No. 83. NICE, London.

National Institute for Health and Care Excellence (2016b) UrgoStart for Chronic Wounds. Medtech innovation briefing No. 82. NICE, London.

National Institute for Health and Care Excellence (2018) Protease-modulating Matrix Dressings. https://bnf.nice.org.uk/woundmanagement/protease-modulating-matrix-dressings.html (Last accessed: 1 February 2018.)

Ng MF (2010) The role of mast cells in wound healing. International Wound Journal. 7, 1, 55-61.

Nursing and Midwifery Council (2015) The Code: Professional Standards of Practice and Behaviour for Nurses and Midwives. NMC, London.

Okonkwo UA, DiPietro LA (2017) Diabetes and wound angiogenesis. International Journal of Molecular Sciences. 18, 7, 1419. doi: 10.3390/ijms18071419.

Ousey K, Atkin L (2013) Optimising the patient journey made easy. Wounds UK. 9, 2, 1-6.

Parks WC (1999) Matrix metalloproteinases in repair. Wound Repair and Regeneration. 7, 6, 423-432.

Phillips PL, Wolcott RD, Fletcher J et al (2010) Biofilms made easy. Wounds International. 1, 3, 1-6.

Pirayesh A, Dessy LA, Rogge FJ (2007) The efficacy of a polyhydrated ionogen impregnated dressing in the treatment of recalcitrant diabetic foot ulcers: a multi-centre pilot study. Acta Chirurgica Belgica. 107, 6, 675-81.

Probst S, Seppãnen S, Gerber V et al (2014) EWMA document: home care-wound care: overview, challenges and perspectives. Journal of Wound Care. 23, Suppl 5a, S1-S41.

Posnett J, Franks PJ (2008) The burden of chronic wounds in the UK. Nursing Times. 104, 3, 44-45.

Price P, Harding K (2004) Cardiff Wound Impact Schedule: the development of a condition-specific questionnaire to assess healthrelated quality of life in patients with chronic wounds of the lower limb. International Wound Journal. 1,1,10-17.

Radek, K., A., Kovacs, E., J., \& DiPietro, L., A. (2007) Matrix proteolytic activity during wound healing: Modulation by acute ethanol exposure. Alcoholism Clinical Experiments Research; 31:1045-1052.

Raguso CA, Kyle U, Kossovsky MP et al (2006) A 3-year longitudinal study on body composition changes in the elderly: role of physical exercise. Clinical Nutrition. 25, 4, 573-580.

Rüttermann M, Maier-Hasselmann A, Nink-Grebe B et al (2013) Local treatment of chronic wounds in patients with peripheral vascular disease, chronic venous insufficiency, and diabetes. Deutsches Ärzteblatt International. 110, 3, 25-31.

Schultz GS, Sibbald RG, Falanga V et al (2003) Wound bed preparation: a systematic approach to wound management. Wound Repair and Regeneration. 11, Suppl 1, S1-S28.

Stacey M (2016) Why don't wounds heal? Wounds International. 7, 1, 16-21.

Sternberg EM (2006) Neural regulation of innate immunity: a coordinated nonspecific host response to pathogens. Nature Reviews Immunology. 6, 4, 318-328.

Sussman G (2014) Ulcer dressings and management. Australian Family Physician. 43, 9, 588-592.

Sylvia CJ (2003) The role of neutrophil apoptosis in influencing tissue repair. Journal of Wound Care. 12, 1, 13-16.

Tchkonia T, Morbeck DE, von Zglinicki T et al (2010) Fat tissue, aging and cellular senescence. Aging Cell. 9, 5, 667-684.

Tønnesen H, Pedersen S, Lavrsen M et al (2012) Reduced wound healing capacity in alcohol abusers - reversibility after withdrawal. Clinical Health Promotion. 2, 3, 89-92.

Visser M, Pahor M, Tylavsky F et al (2003) One- and two-year change in body composition as measured by DXA in a populationbased cohort of older men and women. Journal of Applied Physiology. 94, 6, 2368-2374.

Vowden P (2011) Hard-to-Heal Wounds Made Easy. www.woundsinternational.com/media/issues/514/files/content 10140.pdf (Last accessed: 26 January 2018.) 
Vowden P, Vowden K (2016) The economic impact of hard-to-heal wounds: promoting practice change to address passivity in wound management. Wounds International. 7, 2, 10-15.

123, January, 82-106.

Watret L (2005) Teaching Wound Management: A Collaborative Model for Future Education.

www.worldwidewounds.com/2005/november/Watret/Teaching-Wound-Mgt-Collaborative-Model.html (Last accessed: 1 February 2018.)

Winter GD (1962) Formation of the scab and the rate of epithelialization of superficial wounds in the skin of the young domestic pig. Nature. 193, 293-294.

Wolff, H. \& Hansson, C. (2003) Larval therapy-an effective method of ulcer debridement. Clinical and Experimental Dermatology, 28(2): 134-137.

Wolcott R (2016) Are chronic wounds, chronic infections? Journal of Wound Care. 25, Suppl 10, S3.

World Union of Wound Healing Societies (2008) Diagnostics and Wounds. A Consensus Document. WUWHS, London.

Young L (2016) Improving Patient Outcomes Using Pre-moistened Debridement Cloths on a Chronic Diabetic Foot Ulcer. http://epostersonline.com/wounds2016/node/107 (Last accessed: 1 February 2018.) 